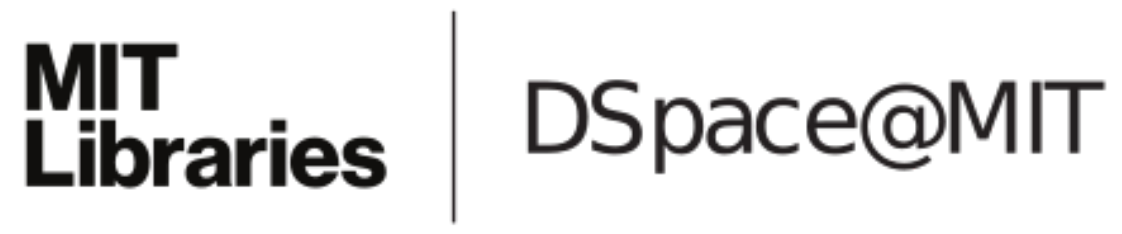

\author{
MIT Open Access Articles
}

Comments on Austronesian nominalism: A Mayan perspective

The MIT Faculty has made this article openly available. Please share how this access benefits you. Your story matters.

Citation: Coon, Jessica. "Comments on Austronesian Nominalism: A Mayan Perspective." Theoretical Linguistics 35, no. 1 (January 2009). 6 Walter de Gruyter

As Published: http://dx.doi.org/10.1515/thli.2009.004

Publisher: Walter de Gruyter

Persistent URL: http://hdl.handle.net/1721.1/108666

Version: Final published version: final published article, as it appeared in a journal, conference proceedings, or other formally published context

Terms of Use: Article is made available in accordance with the publisher's policy and may be subject to US copyright law. Please refer to the publisher's site for terms of use. 


\section{Comments on Austronesian nominalism: A Mayan perspective*}

JESSICA COON

\section{Introduction}

In the conclusion of his article on Austronesian voice and extraction, Kaufman suggests the possibility of extending his analysis of extraction facts in Tagalog to other "syntactically ergative" languages (i.e. languages in which ergative arguments are unable to undergo extraction), such as those in the Mayan family. In this commentary I do not attempt to evaluate Kaufman's claims for Tagalog, but instead explore some of the interesting parallels - as well as important differences-between languages of the Mayan family, and Austronesian languages as analyzed by Kaufman. I discuss ergative-genitive syncretism, nominalization, parallels between the clause and the DP, and extraction facts more generally.

Despite a number of similarities, I first argue that there is clear evidence for a distinction between nouns and verbs in the Mayan family. Second, I address Kaufman's suggestion that nominalism and ergativegenitive syncretism may be at the heart of bans on the extraction of ergative arguments outside of Austronesian languages. The Mayan family provides an interesting testing ground for this proposal, as possessor extraction is attested in some Mayan languages (Aissen 1996; Broadwell 2005; Coon 2009). Though further data is needed in this area, initial

* Many thanks to Norvin Richards for helping clarify some of the Tagalog issues at stake here, and to David Pesetsky and Masha Polinsky for useful comments and discussion. I am grateful to Judith Aissen, Jürgen Bohnemeyer, Sandra Cruz Gómez, Robert Henderson, Lwin Pedro Mateo, Gilles Polian, Roberto Santíz Gómez, Kirill Shklovsky, and Roberto Zavala for discussion of Mayan languages and data. Any errors are of course my own. 


\section{Jessica Coon}

investigation suggests that there may, as Kaufman's proposal suggests, be a correlation between the availability of ergative extraction and the availability of possessor extraction. I begin by summarizing some of the relevant points of Kaufman's article.

\section{Austronesian voice and extraction}

In his article "Austronesian Nominalism and its Consequences", Kaufman proposes that basic Tagalog sentences, like those in (1) do not involve a subject and a verb phrase. Instead, he argues that Tagalog lacks a (lexical) verbal category altogether; the sentences in (1) involve a predication relation between two DPs. In (1a), for example, both the subject ang=púsa and the apparent verb phrase kumáin nang=dagá both belong to a single (nominal) macrocategory. ${ }^{1}$

$$
\begin{aligned}
& \text { a. }\left[\mathrm{k}\left\langle\mathbf{u m}>\text { áin nang=dagà }{ }_{\mathrm{DP}}\right]\left[\mathbf{a n g}=\text { púsa }{ }_{\mathrm{DP}}\right]\right. \\
& \langle\text { AV:BEG }\rangle \text { eat } \mathrm{GEN}=\text { rat } \quad \mathrm{NOM}=\mathrm{cat}
\end{aligned}
$$

'The cat ate a rat.' 'The rat was the eaten one of the cat.'

(Kaufman, 5)

Facts related to the Tagalog voice system form the basis of this article. In the sentence in (1a), the root káin 'eat' is in the agent voice, triggered by the infix $\langle u m\rangle$. The agent, here púsa appears as the subject and is marked with ang-, which Kaufman glosses 'nominative'. The patient appears with the marker nang-, which Kaufman glosses as 'genitive'. In (1b), in contrast, we find the root appearing in the patient voice. The patient argument now appears as the subject and is marked with ang-; the agent is in the genitive case. Other voices are also possible, and the generalization appears to be that any non-subject, non-oblique argument will receive the nang- marker. It is worth pointing out that while Kaufman

1 All Tagalog examples and glosses are taken from Kaufman's article; brackets and category labels are my own. 
glosses nang- as 'genitive', previous works have analyzed this simply as default case (Norvin Richards, p.c.).

The voice system plays an important role in extraction in the language. Namely, in sentences like those in (1), only the ang-marked subject may be questioned, topicalized, or relativized. Arguments marked with nangmay not extract. In other words, in order to extract the agent, the agent voice must be used; to extract the patient, the patient voice must be used, etc. Previous works have proposed that the impossibility of extracting non-subject arguments should be explained as the result of a locality violation (Maclachlan and Nakamura 1997; Chung 1998; Richards 2000, among others). By proposing that the apparent verb phrase is in fact a nominal DP, Kaufman aims to account for extraction facts in the language by reducing the bans on extraction of nang-marked "genitive" arguments to bans on genitives more generally. The ang-marked subjects are based-generated outside of this DP, and are thus free to extract.

Kaufman uses the nominal constructions above to account for bans on extraction of nang- or genitive-marked arguments. For topicalization, he proposes that the ban on extracting a genitive-marked argument is reduced to a ban on extraction of possessors more generally. In (2) we see that it is impossible to extract an agent out of a patient voice construction. For Kaufman, this is due to the fact that the agent, here Boboy is generated as a possessor inside of the predicative DP. Topicalizing the ang-marked argument libro in this construction would be permitted, as we are not extracting out of a DP.

$$
\begin{aligned}
& \text { a. } * \mathbf{N i}=\text { Boboy }_{i} \text { ay }\left[\text { TPP }\left[\mathbf{t}_{i} \mathrm{~b}\langle\text { in }\rangle \text { ili- } \varnothing \quad \text { PRED:DP }\right][\text { ang=libro }\right. \\
& \text { GEN=Boboy TOP } \quad\langle\text { BEG }>\text { buy-PV } \quad \text { NOM=book }
\end{aligned}
$$

Noting that genitive extraction is cross-linguistically very restricted, Kaufman suggests that his analysis of extraction facts in Tagalog may be extended to languages outside of the Austronesian family. Specifically, he notes that many ergative languages show what has been called "syntactic ergativity" - ergative arguments (i.e. transitive agents) are unable to extract, while extraction of absolutive arguments (transitive patients 


\section{Jessica Coon}

and intransitive subjects) is unrestricted. Kaufman notes that in languages with ergative-marking, we often find syncretism between the ergative and another "peripheral case" (Dixon 1994; Palancar 2002). In ergative languages where we find a syncretism between ergative and genitive cases, ergativity is proposed to have arisen from a reanalysis of a nominalization structure (Manning 1996). Based on these findings, Kaufman proposes that in these types of languages, we can reduce bans on the extraction of ergative arguments to bans on the extraction of genitives more generally. Spelling this out, we expect to find:

(3) a. A correlation between ergative-genitive case syncretism and syntactic ergativity; and

b. A correlation between restrictions on the extraction of ergative arguments, and restrictions on the extraction of genitive arguments.

Below I examine these correlations for several Mayan languages. Mayan languages provide evidence against (3a), though the data collected so far suggests that (3b) may be on the right track. I first discuss some of the parallels between languages in the two families, including proposals for nominalization.

\section{Mayan nominalization \& Austronesian nominalism}

Mayan languages share many properties with the Austronesian languages discussed by Kaufman. The Mayan language family is made up of about thirty languages spoken in Mexico, Guatemala, and Belize. ${ }^{2}$ Despite significant grammatical diversity within the family, the majority of Mayan languages show basic predicate initial word orders, lack grammaticalized tense, and exhibit ergative-absolutive alignment patterns - all characteristics which are also found in the Austronesian family.

2 These languages are divided into four major sub-groups: Yucatecan, Huastecan, Western Mayan and Eastern Mayan (Terrence Kaufman, 1974). Western Mayan is further divided into Tzeltalan and Q'anjob'alan, while eastern Mayan is divided into Mamean and K'ichean. Languages from various sub-groups will be discussed below. 
Similarly, the proposal that all lexical items are basically nominal is not unique to Austronesian languages. In Mayan linguistics this claim dates back at least to Seler $(1887,3)$, who writes that "the predicative verbal expressions are identical fundamentally with the nominal expressions designating a possessive relation." More recently, Lois and Vapnarsky $(2006,76)$ note that "there are striking parallels between verbal and nominal phrases in different respects." Some of the more notable parallels are shown by the Chol (Tzeltalan) data in (4) and (5). ${ }^{3}$

Mayan languages mark grammatical relations on the head with two sets of morphemes, traditionally labelled 'set A' (ERGATIVE/GENITIVE) and 'set B' (ABSOLUTIVE). As shown in (4), the set A markers co-index not only transitive subjects, but also possessors. Set B morphemes mark transitive objects as in (4a), and also the single arguments of intransitives and predicate nominal constructions, as in (4b).

(4) $\mathrm{CHOL}$

a. Tyi k-mek'-e-yety.

PRFV A1-hug-TV-B2

'I hugged you.'

b. K-chich-ety.

A1-older.sister-B2

'You are my older sister.'

Another parallel is found in constituent order. Basic order in Chol clauses is VOS/VS (Vázquez Álvarez 2002; Coon in press), as shown in (5a). Just as subjects follow the verb phrase or predicate, possessors follow the possessum, as in (5b). Subjects trigger set A (ERGATIVE) agreement on the predicate; the possessor triggers set A (GENITIVE) agreement on the

3 The Chol data presented here were collected in Chiapas, Mexico with generous support from a National Science Foundation Dissertation Improvement Grant (BCS-0816923). I am very grateful to Chol consultants Virginia Martínez Vázquez, Matilde Vázquez Vázquez, and Doriselma Gutiérrez Gutiérrez. Any mistakes are of course my own.

Glosses in the Mayan family data below are as follows: 1, 2, 3- $1^{s t}, 2^{\text {nd }}, 3^{\text {rd }}$ person; A - set A (ERGATIVE/GENITIVE); AF - agent focus; AP - antipassive; B - set B (ABSOLUTIVE); CP - completive; DEP - dependent (aspect); DET - determiner; DIR - directional; DS directional suffix; EMPH - emphatic; ENC - enclitic; NML - nominal; PRFV - perfective; PL - plural; REC - recent past; RN - relational noun; SG - singular; TV - transitive verb. In some cases, glosses have been modified from those of the original authors for consistency. 
possessum. Because ERGATIVE and GENITIVE are syncretic in the Mayan family, these morphemes are identical - here the third person (pre-vocalic allomorph) $y$-.

(5) a. $\mathbf{Y}_{i}$-om kajpej [ jiñi wiñik $]_{i}$.

A3-want coffee DET man

'The man wants coffee.'

b. $\mathbf{y}_{i}$-uskuñ $\quad[\text { jiñi wiñik }]_{i}$

A3-older.brother DET man

'the man's older brother'

These similarities can be straightforwardly represented as parallels between the DP and the CP (see Szabolcsi 1983, 1994), as shown in (6) and (7) (Coon in press). External subjects and possessors are both generated inside of an external VoiceP projection. The phrasal predicate $v \mathrm{P}$ and the possessum $n \mathrm{P}$ both front to specifiers higher functional projections, TP in the clause, and a DP-internal inflectional phrase, labelled IP. ${ }^{4}$ The argument in Spec,VoiceP triggers set A agreement on the fronted XP. This parallelism offers a natural possibility for explaining the syncretism between the ERGATIVE and GENITIVE morphemes.

(6) Clause:

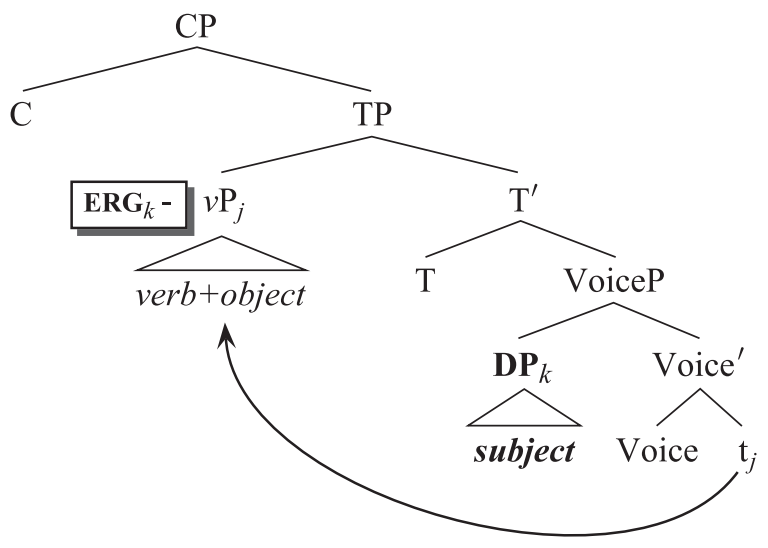

4 Parallelism between the clause and DP may be maintained in which these orders are base-generated. Aissen (1992), for example, argues for an account of Tzotzil Mayan in which both external subjects and possessors are generated in right-hand specifiers. See Coon (in press) for discussion. 
(7) POSESSIVE PHRASE:

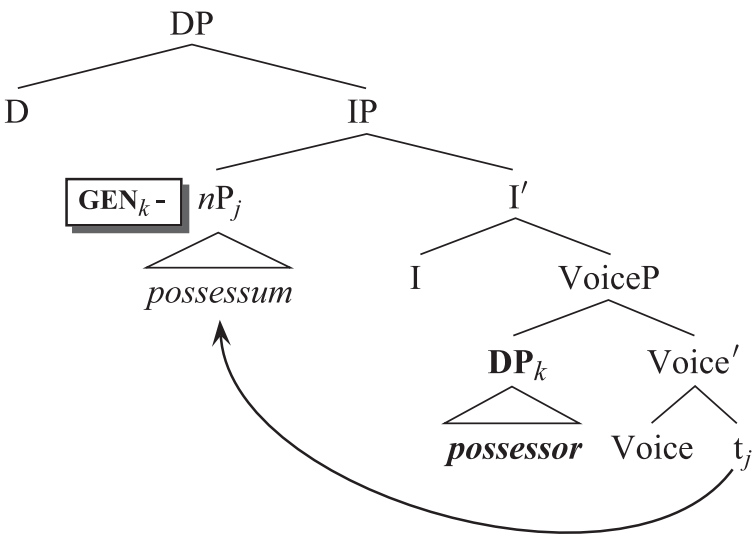

While there are many similarities between verb phrases and noun phrases in Chol, we find clear evidence for a distinction between nominal and verbal forms. These facts connect to Chol's apparent split ergative person marking system, exemplified by the forms in (8) and (9).

(8) ChOl PERFeCtives

a. Tyi i-k'el-e-yoñ. PRFV A3-watch-TV-B1

'She watched me.'

b. Tyi ts'äm-i-yoñ. PRFV bathe-ITV-B1 'I bathed.'
(9) CHOL NON-PERFECTIVES

a. Choñkol i-k'el-oñ. PROG A3-watch-B1 'She's watching me.'

b. Choñkol k-ts'äm-el. PROG A1-bathe-NML 'I am bathing.'

In addition to differences in stem suffixes between perfective and nonperfective aspects, we also find differences in person marking. While both transitives appear with set A co-indexing the subject and set $\mathrm{B}$ coindexing the agent, we see the split in the intransitive forms. In the perfective form in (8b) the subject is co-indexed with the set B (ABSOLUTIVE) marker expected in an ergative-absolutive system. In non-perfective (progressive and imperfective) forms like the one in (9b), however, we find the subject marked with the set A (ERGATIVE/GENITIVE) marker.

The stems also appear in different morphological forms. The perfective takes the suffix $-i$, found on all intransitive eventive predicates, where as the progressive form appears with the suffix -el, found on nominals in Chol and other Mayan languages (Bricker 1981). In Coon (to appear), I argue that 
non-perfective stem forms like kts'ämel in (9b) are in fact nominalizations, represented as in (10). The set A marker here represents the GENITIVE. These nominal forms function as the arguments of a one-place aspectual predicate, here the progressive chonkol. The aspectual predicate behaves as any oneplace predicate in the language in showing set $\mathrm{B}$ agreement with its single argument; since third person set B is null, we do not see it in this example.

(10) CHOL NON-PERFECTIVES

a. Choñkol-Ø [DP i-k'el-oñ ]. PROG-A3 A3-watch-B1

'She's watching me.' 'Her watching me is happening.'

b. Choñkol-Ø [DP k-ts'äm-el ]. PROG-A3 A1-bathe-NML

'I am bathing.' 'My bathing is happening.'

Evidence for this analysis is found in the distributional properties of non-perfective stem forms, which behave as nominals in other contexts (i.e. appear with determiners, after the preposition, and in argument position), as well as the ability of the non-perfective aspect markers to behave as predicates and take non-null set B person morphology in other contexts. Perfective forms as in (10a) do not share these properties: the stem forms are ungrammatical in nominal environments, and the perfective aspect marker does not show the same predicative behavior.

In this proposal for Chol, the non-perfective stem forms are in fact subordinated nominals. A similar pattern is found in clear subordinate clauses in Chol as well as in other Mayan languages, such as Jakaltek (Q'anjob'alan), which show set A person marking of both transitive and intransitive subjects in embedded clauses, as shown in (11). Nominalization as the source of person-marking splits has been suggested for other Mayan languages, for example by Larsen and Norman (1979), MateoToledo (2003), and Mateo (to appear).

(11) JAKALTEK
a. $\mathrm{x}$-Ø-w-ilwe [ hach hin-kol-ni ] ASP-B3-A1-try B2 A1-help-SUF
'I tried to help you.'
b. sab' ichi [ ha-munlayi ] early start A2-work 'You started to work early.'

(Craig 1977: 617) 
If this type of analysis is correct for Chol (and other Mayan languages with aspectual-based person splits), then we have another case where something that has previously been analyzed as the main verb of a clause is in fact a nominal form, as proposed for Austronesian by Kaufman. Specifically, Kaufman proposes that Tagalog sentences in (1) above have a structure like that in (12), where the bracketed elements from (1) represent nominals, related by a null Predicate head (see Richards (this volume) on the status of Tagalog's copula). The agent voice marker $\langle u m\rangle$ occupies a Voice head internal to the predicative DP. The root raises to Voice, where it "fixes its reference to one of the participants in its denotation" (Kaufman, 25). The patient is generated as a complement to the root, where it receives genitive case from $n^{0}$. Crucially for Kaufman's proposal, the subject is base-generated outside of the predicative DP-root complex, as sister to a null predicative tense head; this subject is coindexed with a null operator in Spec,PredP. ${ }^{5}$

(12) TAgAlog AgENT Voice: 'The cat ate a rat.' 'The rat is the cat's eaten one.'

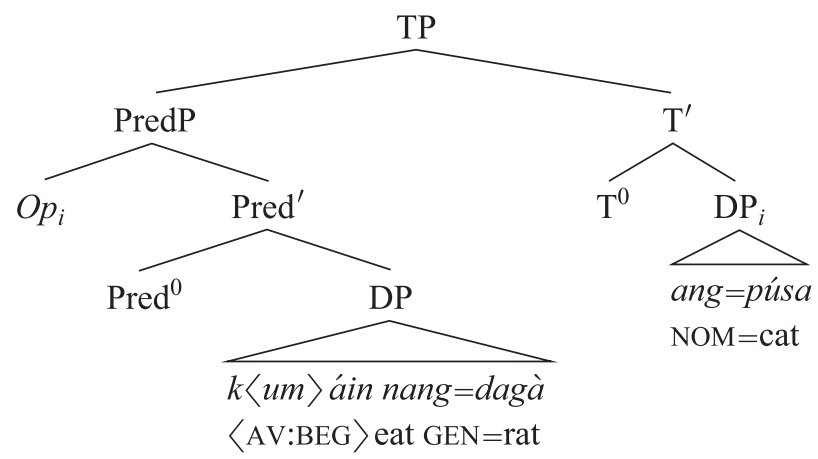

5 Note that under this analysis, the Tagalog subject does not c-command any of the arguments internal to the predicative DP. While I am not in a position to evaluate the Taga$\log$ binding facts, it seems that Kaufman could maintain the core of his analysis in a more standard structure where the subject is generated in Spec,TP and the predicative DP is a sister to the T head. Surface order could be derived either via predicate fronting (as proposed in Rackowski and Travis 2000 and others for Malagasy, and in Massam 2000 for Niuean), or a right-hand subject specifier (proposed for Malagasy by Guilfoyle et al. 1992). 


\section{Jessica Coon}

The analysis of Chol progressive (and non-perfective clauses more generally), is shown in (13). Here the predicate head is the aspectual morpheme choñkol. Unlike Kaufman's structure, in Chol we are dealing with an intransitive construction: the nominalized clause appears as the single (internal) argument of the predicate. The agent, here marked with the third person $i$-, is encoded as a grammatical possessor and triggers the set A GENITIVE marking. In contrast to Kaufman's proposal for Tagalog, all arguments are within the nominalized DP.

(13) ChOL PROGRessive: 'She is watching me.' 'Her watching me is happening.'

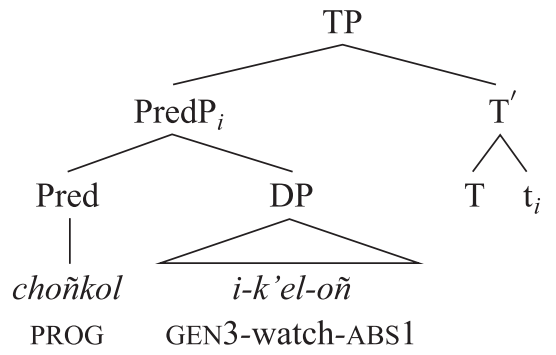

In Mayan languages which show this type of split, we are not dealing with an absence of verbs in the language, but rather the obligatory nominalization of predicates in embedded constructions. While a number of parallels between clauses and nominals do exist in Chol, and in the Mayan family more generally, a reduction of all forms to a single lexical macro-category would leave us unable to account for the morphological and syntactic distinctions found between perfective and non-perfective forms like those in (8) and (9) above.

As noted above, parallels between CPs and DPs have been proposed for other languages, and can explain the similarities between Mayan person marking and word order in clauses and nominals. If, as Kaufman argues, we are dealing not with mere parallels in Austronesian, but a true lack of distinction between nominal and verbal categories, then we expect to find no differences between words that encode traditional verbal information and those that encode nominal information, but see Richards (and others?) (this volume) for a discussion of whether this is correct for Tagalog. ${ }^{6}$ 


\section{Extraction in the Mayan family}

Finally, I turn to extraction facts in the Mayan family. Recall that Kaufman reduces bans on extraction in Tagalog to extraction of genitive arguments more generally. He suggests extending this analysis beyond Tagalog. "It is a promising start," he notes "that the classically syntactically ergative languages, Mayan, Eskimo and Austronesian, all share the genitive-ergative syncretism while Basque, an ergative language with no unexpected extraction asymmetries, shows an ergative-ablative syncretism" (Kaufman, 34). In this section I explore the diversity of extraction facts within the Mayan family to see whether this type of extension is warranted.

\subsection{Genitive extraction}

Note that in the proposed structure for Chol progressives in (13) above, the subject is a grammatical possessor within a nominalized clause. We might expect that progressive agents are thus unable to extract. This however, is not the case, as shown by the forms in (14). In (14a) we find a transitive declarative sentence. The subject triggers set A agreement on the predicate; third person set B is null. In (14b) the agent is questioned with no change to the stem form. These transitive agents may also undergo focus fronting and relativization, not shown here.

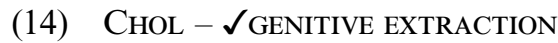

a. Choñkol [DP i-jap kajpej jiñi wiñik ].

PROG A3-drink coffee DET man

'The man is drinking coffee.' 'The man's coffee drinking is happening.'

b. Maxki $i_{i}$ choñkol [DP i-jap kajpej $\left.\mathbf{t}_{i}\right]$ ?

WHO PROG A3-drink coffee

'Who is drinking coffee?' 'Whose coffee drinking is happening?'

6 Masha Polinsky (p.c.) notes that in some Austronesian languages, true nouns can appear with or without a determiner, while nominalized elements require a determiner. This is not expected in an account where all lexical items belong to a single category. 


\section{Jessica Coon}

However, looking at possessive phrases in Chol more broadly, we find that this is in fact expected. As shown by the forms in (15), possessor extraction is possible in Chol. Though Kaufman notes that possessor extraction is widely restricted in the world's languages (Kaufman, 30), it is attested in the Mayan family (Aissen 1996; Broadwell 2005; Coon 2009). In Chol, genitives may extract out of all internal arguments, such as the subject of the unaccusative in (15). Taking the nominalized clauses in (14) to be the internal arguments of the progressive predicate, the extraction of the agent in (14b) is thus predicted.

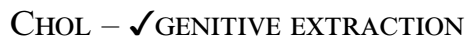

a. Tyi chäm-i [op i-wakax jiñi wiñik ].

PRFV die-ITV A3-cow DET man

'The man's cow died.'

b. Maxki $i_{i}$ tyi chäm-i [op i-wakax $\left.\mathbf{t}_{i}\right]$ ?

WHO PRFV die-ITV A3-cow

'Whose cow died?'

Extraction is available not just for transitive agents in non-perfective clauses (encoded as grammatical possessors), but for set A (ERGATIVE/ GENITIVE) arguments generally. That is, in Chol there is no restriction against extracting ergative (transitive agent) arguments. This can be seen by comparing the declarative transitive in (16a) with the interrogative in (16b) - in (16b) the ergative argument is extracted without the use of a special verb form. Relativization and focus are also possible with ergatives in Chol. ${ }^{7}$

CHOL $-\checkmark$ ERGATIVE EXTRACTION

a. Tyi i-mäñ-ä koya` jiñi $\mathbf{x}-\mathbf{k}$ 'aläl. PRFV A3-buy-TV tomato DET CL-girl 'The girl bought tomatoes.'

b. Maxki $i_{i}$ tyi i-mäñ-ä koya` $\mathbf{t}_{i}$ ? who PRFV A3-buy-TV tomato 'Who bought tomatoes?'

7 Here I will talk about the A-bar extraction of ergative arguments as a unified phenomenon, as it appears to be in Chol, though this may be incorrect for some languages. That is, it is possible that we could find Mayan languages in which ergative arguments may extract in questions, but not in focus constructions. 
This phenomenon is not limited to Chol: while to my knowledge all Mayan languages do show syncretism between ERGATIVE and GENITIVE or 'set A' morphemes (compare for example the Chol examples in (5) above), not all show the extraction asymmetries discussed by Kaufman. In languages across the family, ergative arguments are free to extract. This is true of Chol, Chontal, Tzeltal, and Chorti (Tzeltalan branch); Lacandon, Itzaj, and Mopan (Yucatecan branch); Huastec (Huastecan); as well as in Mocho and Tojolabal (Q'anjob'alan) (Roberto Zavala, p.c.).

While all of these languages allow the extraction of ergative arguments, more work is needed to determine if they all also allow the extraction of genitive arguments, as Kaufman might predict. In Tzeltal, at least, this seems to be the case. Like Chol, Tzeltal does not show a restriction on the extraction of ergative arguments (Robinson 2002); also like Chol, possessors in Tzeltal may extract out of their DPs (Gilles Polian, Roberto Santíz Gómez, p.c.). From the perspective of Kaufman's paper, Chol and Tzeltal are interesting in that they are both morphologically ergative languages in which ERGATIVE and GENITIVE are syncretic. Nonetheless, these languages do not appear to show the syntactic ergativity discussed by Kaufman - ergative arguments are free to extract. Looking outside the Mayan family, we also find languages like Chukchi in which ergative and genitive are not syncretic, and yet the ergative is still unable to extract (Masha Polinsky, p.c.). We thus find that ergative-genitive syncretism must not be directly correlated with syntactic ergativity.

While a correlation between ergative-genitive syncretism and syntactic ergativity is not warranted, Chol and Tzeltal are interesting for Kaufman's proposal that these languages do show evidence for a correlation between the availability of ergative extraction and the availability of genitive extraction: both are possible. It would be interesting to look at some of the languages outside of the Tzeltalan branch in which ergative extraction is possible (e.g. Itzaj, Huastec, Tojolabal) to see if this is a more widespread phenomenon.

\subsection{Agent focus and antipassive}

Now we turn to the so-called "syntactically ergative" Mayan languages, in which the extraction of ergative arguments is either impossible or 
restricted. In languages of this type, in order to extract a transitive agent, the verb form must first be detransitivized. The agent then triggers set $\mathrm{B}$ (ABSOLUTIVE) agreement (rather set A ERGATIVE agreement), and is free to extract. In some Mayan languages, this process involves an antipassive construction in which the agent triggers set $\mathrm{B}$ absolutive agreement on the detransitivized predicate and the patient is demoted (i.e. oblique or simply absent). In other languages we find the verb appearing in what has been called an agent focus (AF) form. Agent focus differs from antipassive in that in the agent focus the patient need not be demoted. Aissen (1992) argues that while antipassive forms are both syntactically and morphologically intransitive, AF constructions are morphologically intransitive, but retain their syntactic transitivity. See Aissen (1999), Stiebels (2006), and works cited therein for a detailed discussion of these facts.

4.2.1. Agent focus. Q'anjob'al is a language in which we find a contrast between the extraction of ergative and absolutive arguments. In (17a), the absolutive object is extracted. Here the transitive verb maq' appears in its unmarked form and shows set A agreement with the agent. In (17b) the agent is extracted. Now the verb must appear with the detransitivizing suffix -on and may no longer show set A (ERGATIVE) agreement. That is, the extracted agent triggers set $\mathrm{B}$ agreement; the patient shows no agreement. This same type of construction is required when the transitive agent is relativized or focussed. Note that because the object in (17b) is still present and is not oblique, this is considered a type of agent focus and not a true antipassive (see Mateo-Toledo 2008 for more discussion).

Q'ANJOB'AL - RESTRICTED ERGATIVE EXTRACTION

a. maktxel max-Ø s-maq' naq winaq? who CM-B3 A3-hit CL man 'Who did the man hit?'

b. maktxel max- $\varnothing$ maq'-on naq winaq?

who CM-B3 hit-AF CL man

'Who hit the man?'

(Mateo 2009)

Interestingly, while Q'anjob'al does show a ban on the extraction of ergative-marked arguments, the extraction of genitive arguments is possible, as shown by the forms in (18). 


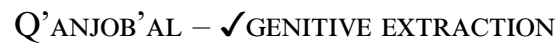

a. max- $\varnothing$ h-el [s-nwej ix Malin ] COM-B3 A2-see A3-sister CL Maria

'You saw Maria's sister.'

b. maktxel max- $\varnothing$ h-el [s-nwej $\left.\mathbf{t}_{i}\right]$ ? who CM-B3 A2-see A3-sister

'Whose sister did you see?'

(Pedro Mateo, p.c.)

However, in Q'anjob'al the agent focus is possible only with third person arguments. Mateo-Toledo $(2008,76)$ notes that "non-third persons are focussed in other ways, such as with an active form." It thus appears that the extraction of ergative arguments in Q'anjob'al is not completely banned, but restricted.

Similar facts are found in Tzotzil (Tzeltalan). In Tzotzil, as discussed in Aissen (1999), the extraction of ergative arguments is also restricted, though not entirely impossible. In contexts where the extraction of the ergative argument is prohibited, the agent focus must be used. An example of a construction which requires the AF is shown in (19). In (19a) the transitive agent is extracted and the verb shows the -on agent focus suffix. The equivalent sentence in (19b) with no AF suffix is ungrammatical.

(19) TZOTZIL - RESTRICTED ERGATIVE EXTRACTION

a. K'usi i-ti'-on?

what CP-eat-AF

'What bit him?'

b. * K'usi i-s-ti'?

what CP-A3-eat

(grammatical with the meaning 'what did he eat?')

(Aissen 1999, 459)

Despite showing restrictions on the extraction of certain ergative arguments, Tzotzil does permit possessors to extract, as shown by the forms in (20). Like Chol, possessor extraction is possible out of absolutive arguments (Aissen 1996).

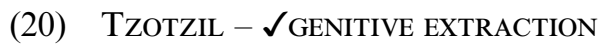

a. I-cham x-ch'amal li Xun-e.

CP-died A3-child the Xun-ENC

'Xun's child died.' 
b. Buch'u $u_{i}$ i-cham [ $\mathrm{x}$-ch'amal $\left.\mathrm{t}_{i}\right]$ ?

who CP-die A3-child

'Whose child died?'

(Aissen 1996, 456)

Like Tzotzil and Q'anjob'al, K'ichee' (K'ichean) restricts the extraction of ergative arguments in some contexts (Stiebels 2006; Robert Henderson p.c.), but does permit possessor extraction out of intransitive clauses (Broadwell 2005). I do not review the K'ichee' data here for reasons of space.

Though these data may look problematic for Kaufman's proposed connection between ergative and genitive extraction, the situation is in fact more complicated. As noted above, in agent focus constructions like those in Q'anjob'al and Tzotzil, the object need not be demoted to oblique status. Aissen (1999) argues that in Tzotzil, the agent focus construction involves a verb form which is syntactically and semantically transitive, and only morphologically intransitive. Furthermore, she proposes that the use of AF in Tzotzil is determined by the relative prominence of the agent and patient - specifically, the AF form requires that the object outrank the subject in prominence (Aissen 1999, 459). K'ichee' similarly permits ergative extraction with no AF in certain contexts based on the relative rank of arguments (Mondloch 1981, cited in Stiebels 2006).

While discussions of AF constructions in Mayan languages have often been seen as evidence for syntactic ergativity (cf. Larsen and Norman 1979; England 1983a), Aissen shows that in Tzotzil the AF constructions are more closely connected to systems of inverse and obviation, like those found in Algonquian languages. That is, the verb form used for the extraction of ergative arguments is governed perhaps not by the syntactic position of ergatives, but by their relative placement along a nominal hierarchy. If this is the case then it is not clear that the agent focus constructions will tell us anything deep about the nature of ergative extraction.

4.2.2. Antipassive. An example of the antipassive is found in Mam (Mamean branch). In Mam ergative agents cannot be questioned out of a transitive verb stem. Instead, the antipassive, marked by the suffix $-n$ must be used. This is shown by the Mam forms in (21). In the active tran- 
sitive in (21a), the verb appears with both ergative and absolutive markers co-indexing the subject and object respectively. When the patient is questioned in (21b), the verb form remains the same. In (21c) the agent is questioned, and the antipassive construction is obligatory. As in the AF constructions above, the detransitivized verb shows agreement with the agent via the absolutive marker. Here however, the patient must appear in an oblique phrase (in brackets), representing an case of true syntactic intransitivity. Furthermore, in Mam ergative extraction seems to be always banned, regardless of the person or relative rank of arguments.

(21) Mam - *ergative eXtraction
a. ma-a7 chi tzaj t-tzyu-7n Cheep kab' xiinaq REC-EMPH B3.PL DIR A3.SG-grab-DS José two man 'José grabbed the men.'
b. alkyee-qa $\mathrm{x}$-chi tzaj t-tzyu-7n who-PL REC.DEP-B3.PL DIR A3.SG-grab-DS José 'Whom did José grab?' Cheep?
c. alkyee $x-\varnothing$-tzaj tzyuu-n [ ky-e kab' xiinaq ]? who REC-DEP-b3.sg-DIR grab-AP 3.PL-RN two man 'Who grabbed the men?'

(England 1983b, 250)

At the time of writing, I was unable to determine conclusively whether the extraction of possessors out of possessive phrases is possible in Mam. In her grammar, England notes that the "question of all nominals except direct agents and patients is obligatorily expressed in relational noun phrases" (England 1983b, 251), which may suggest that it is impossible, though I found no examples of a possessor questioned out of a possessive phrase.

England also discusses possessor focus, noting that "contrastive emphasis of the possessor can be expressed through double possession" (possession morphologically marked twice on the possessum), as shown by the examples in (22). (22a) is given as a "focus" construction. Here the possessed noun remains post-verbal but receives double marking ( $n$ - and $w$ - are listed as allomorphs of the first person set A marker in Mam). In (22b) England gives an example of a "focus and topicalization" construction where the possessive phrase is fronted and one of the markers appears post-nominally. 
(22) MAм
a. ma Ø-kub' tiil-j w-n-jaa
REC A3.SG-DIR knock.down-PAS A1.SG-A1.sG-house
' $M y$ house was knocked down.'
b. n-jaa-wa ma $\varnothing$-kub' tiil-j
A1.SG-house-A1.SG REC B3.SG-DIR knock.down-PAS
'It was $m y$ house that was knocked down.'

(England 1983b, 144)

If possessor extraction were possible in Mam, we might expect to see an overt pronoun fronted to a pre-verbal position and the possessum jaa 'house' left post-verbally. Further work is needed to determine whether this is possible. Mam - and other languages which have a true antipassive (Aissen 1999 lists Q'eqchi' and some dialects of K'ichee') - could provide interesting additional test cases for Kaufman's proposal.

\section{Conclusion}

Both Mayan and Austronesian show a number of parallels between nominals and verbal forms. While reducing all lexical items to a single category is not warranted for Mayan (or at least for Chol and other languages with splits involving nominalization), the connection between the extraction of ergative arguments and the extraction of genitive arguments deserves further detailed investigation. The findings discussed here are summarized in (23).

\begin{tabular}{l||l|ll}
\hline & $\begin{array}{l}\text { ERGATIVE-GENITIVE } \\
\text { syncretism }\end{array}$ & $\begin{array}{l}\text { ERGATIVE } \\
\text { extraction }\end{array}$ & $\begin{array}{l}\text { GENITIVE } \\
\text { extraction }\end{array}$ \\
\hline \hline Chol & $\checkmark$ & $\checkmark$ & $\checkmark$ \\
Tzeltal & $\checkmark$ & $\checkmark$ & $\checkmark$ \\
\hline Q'anjob'al & $\checkmark$ & restricted & $\checkmark$ \\
Tzotzil & $\checkmark$ & restricted & $\checkmark$ \\
K'ichee' & $\checkmark$ & restricted & $\checkmark$ \\
\hline Mam & $\checkmark$ & $*$ & $*(?)$ \\
Q'eqchi' & $\checkmark$ & $*$ & $?$
\end{tabular}


Both Chol and Tzeltal allow the extraction of both ergatives and genitives. This provides evidence against Kaufman's suggestion that languages in which ergative and genitive are syncretic will show a ban on the extraction of ergative arguments. Q'anjob'al, Tzotzil, and K'ichee' also permit genitive extraction, though the ergative-extraction facts are complicated by the agent focus construction, which at least in Tzotzil may have more to do with relative rank on a person hierarchy than with any sort of deep ergativity. Further investigation into languages with true antipassives, such as Mam, would provide important data for this proposal.

If this connection between ergative extraction and genitive extraction is valid, the question remains as to what this tells us about ergativity. As discussed above nominal phrases and clauses share properties in many languages. This correlation could thus be explained in terms of similar structure between the DP and the CP (i.e. possesors and agents generated in similar structural positions), rather than by the reduction of all lexical items to a single macrocategory, a step which is not justified for the Mayan family and deserves further detailed investigation in Austronesian.

\section{Massachusetts Institute Technology jcoon@mit.edu}

\section{References}

Aissen, Judith. 1992. Topic and focus in Mayan. Language 68:43-80.

Aissen, Judith. 1996. Pied-piping, abstract agreement, and functional projections in Tzotzil. Natural Language and Linguistic Theory 14:447-491.

Aissen, Judith. 1999. Agent focus and inverse in Tzotzil. Language 75:451-485.

Bricker, Victoria R. 1981. The source of the ergative split in Yucatec Maya. Journal of Mayan Linguistics 2:83-127.

Broadwell, George Aaron. 2005. Pied-piping and optimal order in kiche (k'iche'). Ms. University at Albany, State University of New York.

Chung, Sandra. 1998. The syntax of agreement. Chicago: University of Chicago.

Coon, Jessica. 2009. Interrogative possessors and the problem with pied-piping in Chol. Linguistic Inquiry 40:165-175.

Coon, Jessica. in press. VOS as predicate fronting in Chol. In Lingua. doi: 10.1016/j.lingua. 2008.07.006.

Coon, Jessica. to appear. Rethinking split ergativity in Chol. In International Journal of American Linguistics. 


\section{Jessica Coon}

Craig, Collette Grinevald. 1977. The structure of Jacaltec. Austin: University of Texas Press. Dixon, R. M. W. 1994. Ergativity. Cambridge: Cambridge University Press.

England, Nora. 1983a. Ergativity in Mamean (Mayan) languages. International Journal of American Linguistics 49:1-19.

England, Nora. 1983b. A grammar of Mam, a Mayan language. Austin: University of Texas Press.

Guilfoyle, Eithne, Henrietta Hung, and Lisa Travis. 1992. Spec of IP and spec of VP: Two subjects in Austronesian languages. Natural Language and Linguistic Theory 10:375414.

Kaufman, Terrence. 1974. Meso-american Indian languages. Encyclopaedia Brittanica 22:767-774.

Larsen, Tomas W., and William M. Norman. 1979. Correlates of ergativity in Mayan grammar. In Ergativity: Towards a theory of grammatical relations, ed. Frans Plank, 347-370. London/New York: Academic Press.

Lois, Ximena, and Valentina Vapnarsky. 2006. Root indeterminacy and polyvalence in Yukatekan Mayan languages. In Lexical categories and root classes in Amerindian languages, ed. Ximena Loix and Valentina Vapnarsky, 69-115. Bern: Peter Lang.

Maclachlan, Anna, and Masanori Nakamura. 1997. Case-checking and specificity in Tagalog. The Linguistic Review 14:307-333.

Manning, Christopher. 1996. Ergativity: Argument structure and grammatical relations. Stanford, CA: Center for the Study of Language and Information.

Massam, Diane. 2000. VSO and VOS: Aspects of Niuean word order. In The syntax of verb initial languages, ed. Andrew Carnie and Eithne Guilfoyle, 97-116. Oxford: Oxford University Press.

Mateo, Pedro. 2009. Revisiting split ergativity in Q'anjob'al. Paper presented at SULA 5: Semantics of Underdocumented Languages of the Americas.

Mateo, Pedro. to appear. Nominalization in Q'anjob'al Maya. In Kansas working papers in linguistics. University of Kansas. Ms. University of Kansas.

Mateo-Toledo, B'alam Eladio. 2003. Ergatividad mixta en Q'anjobal (Maya): Un reanálisis. In Proceedings of the Conference of Indigenous Language of Latin America 1.

Mateo-Toledo, B'alam Eladio. 2008. The family of complex predicates in Q'anjob'al (Maya): Their syntax and meaning. Doctoral Dissertation, University of Texas Austin, Austin, TX.

Mondloch, James. 1981. Voice in Quiche-Maya. Doctoral Dissertation, SUNY Albany.

Palancar, Enrique. 2002. The origin of agent markers. Berlin: Akademie Verlag.

Rackowski, Andrea, and Lisa Travis. 2000. V-initial languages: X or XP movement and adverbial placement. In The syntax of verb initial languages, ed. Andrew Carnie and Eithne Guilfoyle, 117-142. Oxford: Oxford University Press.

Richards, Norvin. 2000. Another look at Tagalog subjects. In Formal issues in Austronesian linguistics, ed. Ileana Paul, Vivianne Phillips, and Lisa Travis, 105-116. Dordrecht, The Netherlands: Kluwer Academic Publishers.

Robinson, Stuart. 2002. Constituent order in Tenejapa Tzeltal. International Journal of American Linguistics 68:51-80.

Seler, Eduard. 1887. Das Konjugationssystem der Maya-Sprachen, volume 1 of Reprinted in: Collected Works in Mesoamerican Linguistics and Archaeology 1990. Culver City, CA: Labyrinthos, 2nd edition.

Stiebels, Barbara. 2006. Agent focus in Mayan languages. Natural Language and Linguistic Theory 24:501-570. 
Szabolcsi, Anna. 1983. The possessor that ran away from home. The Linguistic Review 3:89102.

Szabolcsi, Anna. 1994. The noun phrase. In Syntax and semantics, vol 27: The syntactic structure of Hungarian, ed. Ferenc Kiefer and Katalin É. Kiss, 179-275. New York: Academic Press.

Vázquez Álvarez, Juan J. 2002. Morfología del verbo de la lengua chol de Tila Chiapas. M.A. thesis, CIESAS, México. 